\title{
READING HYPERMEDIA NARRATIVE STARS, 88 CONSTELLATIONS FOR WITTGENSTEIN BY DAVID CLARK. ANALYTICAL APPROACH TO CONSTELLATION 18 CASSIOPEIA
}

Nohelia Meza*

\begin{abstract}
This article presents an approach to analyze hypermedia discourse elements found in Cassiopeia, one of the constellations that compose 88 Constellations for Wittgenstein (To Be Played with the Left Hand) (2011) by net.art artist David Clark. Even though there are many approaches to the subject of electronic literature, there are still many unexplored e-lit works waiting to be studied that undoubtedly will raise questions about the literariness of electronic literature. This article briefly outlines issues of representation, temporality, semiotics, interaction, and manipulation on this specific constellation of the aforementioned e-lit work. Specific new media literary theories (temporal possibilities in programmed texts; temporal levels for cybertexts with narrative content; pluricode couplings, lability of digital works) have been applied to the selected corpus in order to examine the nuances and gradations of electronic textuality and literary reception. The analysis shows that the user's manipulation and interaction with the e-lit work affect certain elements in the hypermedia narrative discourse so as to suggest new possibilities of temporal and semiotic interpretation.
\end{abstract}

KEYWORDS: Discourse Analysis. Electronic Literature. Narrativity. Semiotics. Temporality.

\section{Introduction}

In this article, I present an analytical approach to constellation number 18, Cassiopeia, one of the star clusters that composes David Clark's e-lit work, 88 Constellations for Wittgenstein (To Be Played with the Left Hand) (2011). The article is organized in two sections; in the first one, I describe the following topics: the reading pathway I have chosen to follow in order to analyze the e-lit work, the general structure of Clark's electronic oeuvre (paratextual and semiotic description), and finally the possible methods and strategies that can be used when navigating through the constellation map. The second section focuses on briefly exploring hypermedia discourse elements found in Cassiopeia itself. This section is divided into four subsections. The first examines the examples of intertextuality and polyphony found in the constellation's narrative discourse. The second aims at understanding how temporal issues can be studied in these new literary creations (KOSKIMAA,

\footnotetext{
*Universitat Pompeu Fabra, España. 
2010); the third explores the "pluricode couplings" that spring from the hypermedia discourse, as well as the rhetoric effects that these couplings may have on the e-lit work's meaning construction due to its lability properties (SAEMMER 2009; 2012; 2013); and, finally, subsection number four presents the reader's manipulation and interaction possibilities with the e-lit work and, more importantly, how these actions affect other elements in the hypermedia narrative discourse itself.

\section{Navigating across 88 Constellations for Wittgenstein (To Be Played with the Left Hand)}

To begin, it is necessary to specify the pathway it has been followed in order to study David Clark's e-lit work. Given the 88 possibilities to approach 88 Constellations for Wittgenstein (To Be Played with the Left Hand) (2011), I have decided to create my own reading path based on the following set of constellations: 18 Cassiopeia (Cassiopeia), 12 Ursa Minor (Constellations), 59 Hydra (The Limits of Language), 04 Orion (Ludwig Wittgenstein). However, for this article, I have chosen to present only the analysis of constellation 18 Cassiopeia (Cassiopeia). It is helpful to mention that each step (click) in the reading path has been labeled with a figure number in order to simulate the reader's action when experiencing the e-lit work. Therefore, Clark's presentation of $88 \mathrm{C}$-this abbreviation will be used throughout the whole article to refer to the e-lit work - corresponds to figure 1 ; the introductory video of $88 \mathrm{C}$ corresponds to figure 2; the main constellation map (departure point) corresponds to figure 3; and so forth. Additionally, the audio transcriptions that belong to the pathway of the selected constellation are provided for the reader's better understanding of the e-lit work; along the following sections, a parenthesis indicating the number of the corresponding transcription is placed on the left side of the quote.

Previous to the main constellation map, the reader experiences two scenarios that can be described as the antechamber of $88 \mathrm{C}$. Following the Electronic Literature Collection Vol. 2 (ELC2) pathway, the reader immediately encounters Clark's own presentation of $88 \mathrm{C}$. Set in black and white background, the spatial presentation is composed of the following semiotic forms: a leading icon combining two texts (the title of the work and the name of the author), this is an example of what Gérard 
Genette defined as peritexts, "elements within the same volume of the text" (1997, p. 4-5.) (my emphasis). In this case, the peritexts contain a hyperlink that instantly starts the e-lit work, and redirects the reader to the introductory video of $88 \mathrm{C}$. There are also three additional linguistic texts that stand as examples of epitexts, defined by Genette as, "the distance elements that are located outside the book" (idem) (my emphasis). The first one labeled, "Blog" redirects to a blog created by Clark that discusses $88 \mathrm{C}$ specifically (i.e. epitext); the second one labeled, "Chemical Pictures" redirects to Clark's personal blog —named "Chemical Pictures" as well—, where the reader learns about other projects and writings by the author (i.e. epitext); and the third one labeled, "A is for apple" redirects to Clark's previous net.art project "A is for Apple" (2002) (i.e. epitext).

Fig. 1 - David Clark's Presentation of 88 Constellations for Wittgenstein

(To Be Played with the Left Hand).

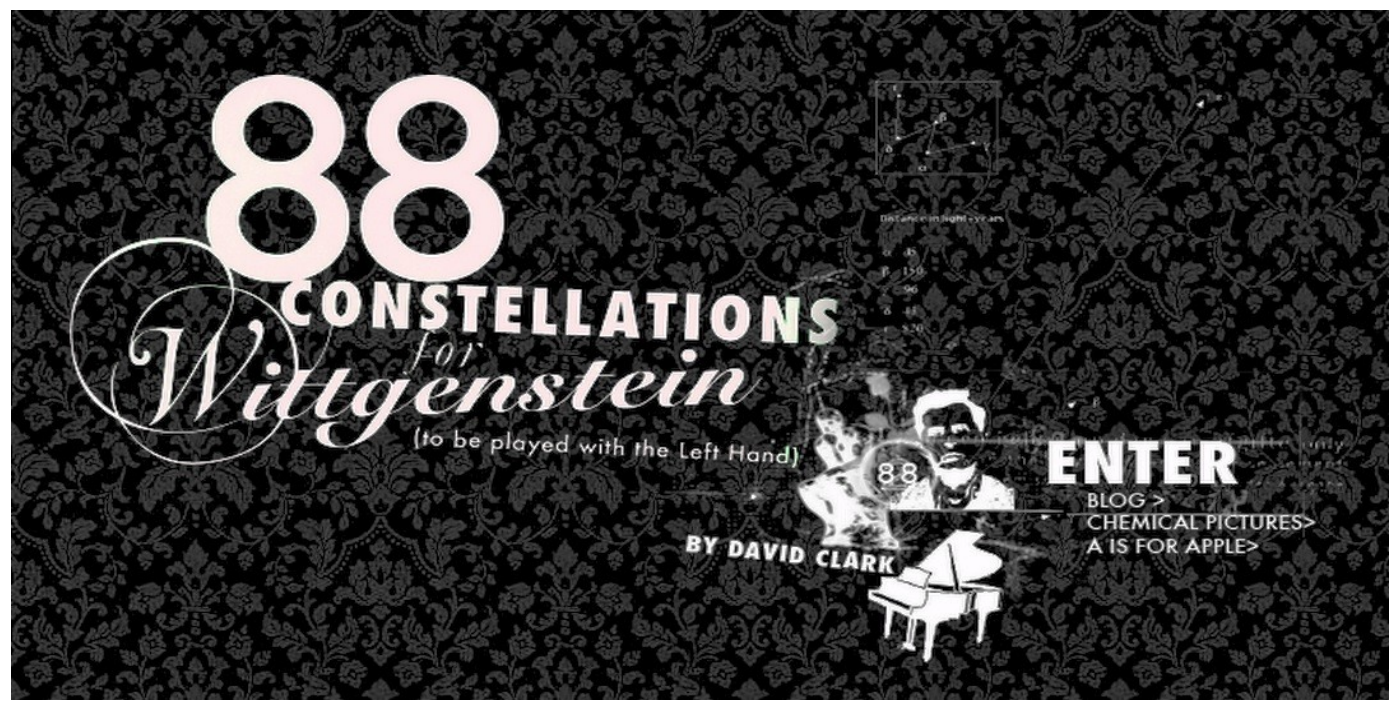

Source: <http://88constellations.net/>.

Moreover, it is inviting to take a minute and observe the additional denotative icons (i.e. peritexts) that compose the black and white front page of $88 \mathrm{C}$, where a rich scenario of art and culture is found: Rodin's sculpture Le penseur, 1[88]0; a grand piano; Wittgenstein's silhouette; the number 88 circled in a white sphere signifying the 88 constellations in the sky, the 88 keys of a piano, a double representation of the infinity symbol $[\infty \infty]$, and Wittgenstein's date of birth 1[88]9. Besides, there is an image of Cassiopeia's constellation that alludes to the letter "W" which creates a 
visual association in the reader's mind to the same letter in "Ludwig Wittgenstein", clearly constructing an intertextual visual effect; and finally, the image of a list of numbers showing the corresponding distance in light years of each of Cassiopeia's stars Ludwig Wittgenstein (Epsilon Cassiopeiae), Coded Remarks (Delta Cassiopeiae), LOL (Gamma Cassiopeiae), Cambridge (Beta Cassiopeiae), Constellations (Alpha Cassiopeiae). It is important to mention that in his own presentation of $88 \mathrm{C}$ outside the ELC2's description of the e-lit work, Clark draws hints and clues via icons, images, and allusions that will certainly come across the reader's explorative navigating later.

It must be noted that in David Clark's own presentation of $88 \mathrm{C}$ there are neither sounds nor videos. This part of the antechamber of $88 \mathrm{C}$ possesses a highly symbolic yet silent atmosphere. It is not until the reader decides to continue exploring the e-lit work by clicking on the linguistic text "ENTER" that she experiences new features of expression; the screen is occupied by moving images, moving letters, digitized speech, sound effects, and music. This description makes reference to the first Flash video of the e-lit work (Fig 2.). The video lasts approximately 40 seconds (40"); the duration of the video is relevant when talking about temporality, since this time will be considered within the reading time, true time, and system time (Cf. 2.2.).

Furthermore, it must be underlined that the option "skip" is provided in the bottom right corner of the screen. If the reader decides to click on it, she will be redirected to the main constellation map (Fig. 3.). Nonetheless, in my opinion, the video is introductory, explanatory, and helpful. For that matter, I considered it as the formal oral introduction to Clark's electronic oeuvre (i.e. peritext). Firstly, by means of a voice-over, the reader encounters the omniscient narrator for the first time; secondly, if the reader pays close attention to the spoken words, moving letters, and moving images, a brief but instructive description of the e-lit work is provided; and thirdly, it is the first time that $88 \mathrm{C}$ is referred to as a "story" by the narrative voice, which suggests that the reader's explorative journey includes discovering the features of story, discourse and narration (GENETTE, 1980, p. 25-32) throughout the night sky. 
(1) Join the dots...join the dots together...make pictures in the sky...connect the model of our thinking to these drawings in the sky...this story is about a man named Wittgenstein...he was a philosopher...his life was a series of moments and our story is a series of constellations. (88C, transcription of introductory video) (my emphasis)

By listening to the video's (oral) text, the reader gets directions from the narrative voice on how to navigate through the e-lit work; the imperatives, "join the dots together" (repeated several times), "make pictures in the sky", "connect the model of our thinking to these drawings in the sky"; prepare the reader for the tasks she will perform during her expedition across the constellations of signs that build up the "story" surrounding Wittgenstein's life. I emphasize the word "story" because it is essential for the reader to comprehend how the story of $88 \mathrm{C}$ is recounted; how the involvement of the narrator is vital throughout the whole text, given that he is the leading voice of the narrative (from which the multivoicedness will spring) (Cf. 2.1.), and furthermore, how the semiotic systems are mingled together when connecting each explorative star in order to construct the hypermedia narrative discourse; new conditions of writing that are best described as follows.

\footnotetext{
These semiotic systems comprise text, graphics, digitized speech, audio files, animation, and film. Produced, for example, by means of HTML, Javascript, Flash, and Shockwave technologies, hypermedia is characterized by a variety of pastiche and collage techniques. (ENSSILIN, 2014, p. 262)
}

Taking this into account, it must be mentioned that the video is composed of other semiotic systems that emerge as flying and twinkling objects in the screen. In terms of linguistic text, there is the title, and the name of the author at the beginning of the video; the name "Ludwig Wittgenstein" appears in the middle; also the emphasis in capital letters of the phrase "JOIN THE DOTS", at the end. In terms of evocative images, there is the constellation 04 Orion (which the reader later learns is devoted to Ludwig Wittgenstein's biography), a left hand (referring to both Wittgenstein's brother Paul, and the additional manipulation features of the e-lit work as specified in its title: "To Be Played with the Left Hand") (i.e. performative peritext), a sphere showing latitudes and longitudes, a grand piano, an elephant, a telescope, the number 88 , various constellations joined by connecting dots, a picture of adult 
Wittgenstein, the symbol of money, the symbol of the Roman God Mars signifying the male sex, a spider, the silhouette of an unknown man, the silhouette of Charlie Chaplin (b. 1[88]9), a rhinoceros, a building, Rodin's sculpture Le penseur (1[88]0), a globe, a duck, and a silhouette of two women featuring the number 88 , to name a few.

Fig. 2 - Screen shots from video 1 shown in order of appearance (upper left, upper right, bottom left, bottom right), 88 Constellations for Wittgenstein (To Be Played with the Left Hand).

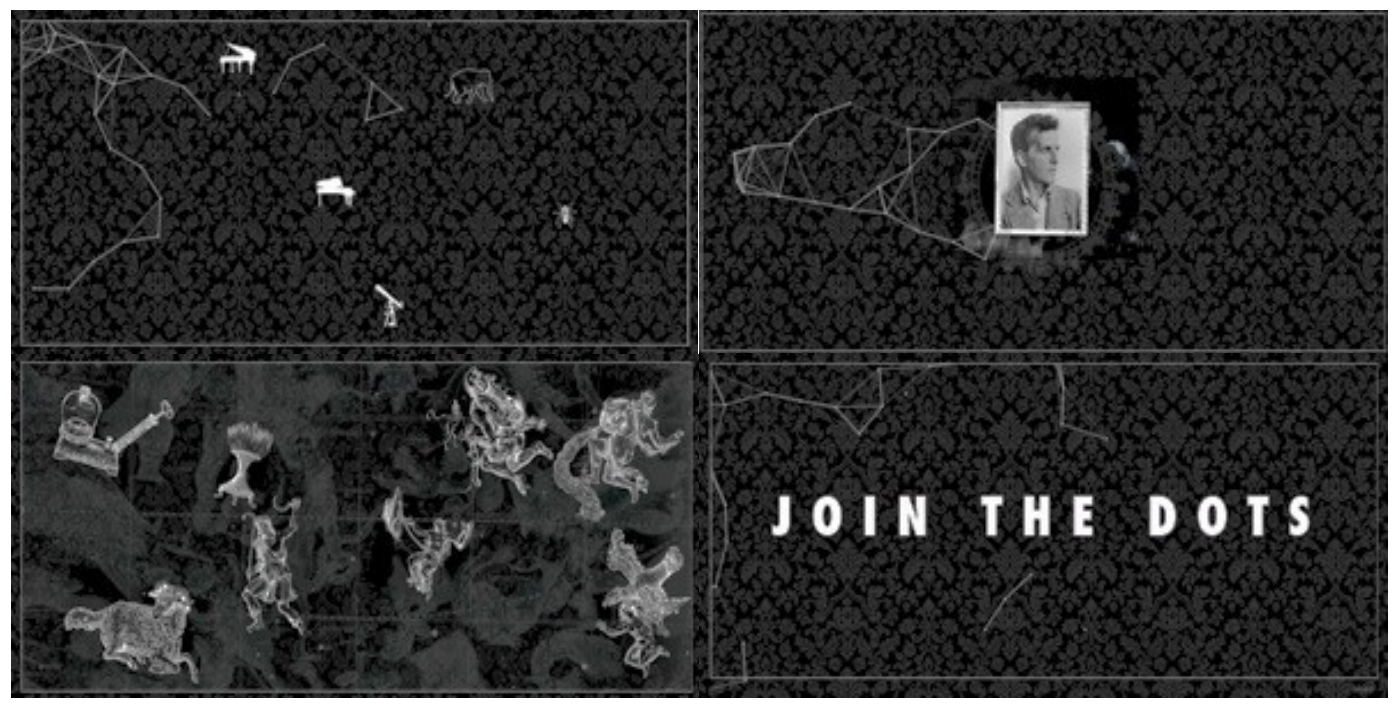

\section{Join the Dots}

The traces of interaction and manipulation found in the antechamber of $88 \mathrm{C}$ are few. It can be said that the main example of interaction is, on the one hand, to activate links in order to reach the principal scenario of the e-lit work (the constellation map) and, on the other hand, to obtain additional information about the author (i.e. epitexts). Given that the act of manipulation when reading electronic literature is based on the reader's interaction with the semiotic forms (text, image, sound, video) (BOUCHARDON, HECKMAN, 2012, Introduction), it must be underlined that in figure 1 and figure 2, the reader's single interaction is depicted by the use of textual linguistic explorative links. The reader does not interact nor manipulate other semiotic forms. As of now, the reader is more a viewer - as pointed out by Clark in the author's description found in the ELC2-, "Each constellation becomes a navigation device for the viewer to negotiate the associative relationships between these 
vignettes" (CLARK, 2011, description of 88C within the ELC2, http://collection.eliterature.org/2/works/clark_wittgenstein.html) (my emphasis). Since, there is no possibility to manipulate any other elements, the reader must observe and listen; not even time can be manipulated at this point, given that the introductory video starts, runs, and finalizes without giving the opportunity of being paused, rewound, or stopped.

The purpose of the explorative links is to construct the path to enter the e-lit work or, if wished, to deviate the path to access alternative texts. Still, "turning a page doesn't involve any particular interpretation of the text" states Yves Jeanneret, "on the contrary, in an interactive work, clicking on a hyperword or an icon is itself an interpretative act. The interactive gesture is primarily the actualization of an interpretation through a gesture." (JEANNERET, 2000, p. 113; cited on BOUCHARDON, HECKMAN, 2012, part 2). Therefore, the significance of the interaction up to this point is to interpret the paratexts and semiotic forms that compose the antechamber of $88 \mathrm{C}$ through the one click away co-construction of a new narrative experience and meaning. Let the reader not forget that, as suggested by Clark, there is no other way to interlace the story of Ludwig Wittgenstein than by "joining the dots together, making pictures in the sky (mind), and connecting the model of our thinking to these drawings in the sky" (88C, transcription 1).

\section{The Constellation Map}

The map is composed of 88 constellations set on a starry night background. There is a sound that resembles a drum and simultaneously creates an atmosphere of continuity while the reader chooses the constellation to be explored; the music is composed of a repetitive tune that lasts as long as the reader surfs and hovers the pointer over the night sky. This music possesses a temporal effect that adds expectation and suspense to the narrative. The reader realizes that her journey is not only a visual meaning-making experience, but also an aural meaning-making one. As the reader moves the mouse through the landscape of both Southern and Northern hemispheres, she explores not only the original names of each constellation, but also the thematic name Clark has given to each constellation in order to underline an 
specific topic; additionally, an abbreviation in the surface of each constellation is depicted; e.g. "Cassiopeia (CAS): Cassiopeia"; "Ursa Minor (UMI): Constellations"; "Hydra (HYA): The Limits of Language"; "Orion (ORI): Ludwig Wittgenstein”.

Fig. 3 - Constellation Map Showing Constellation 18 Cassiopeia (Cassiopeia), 88 Constellations for Wittgenstein (To Be Played with the Left Hand).

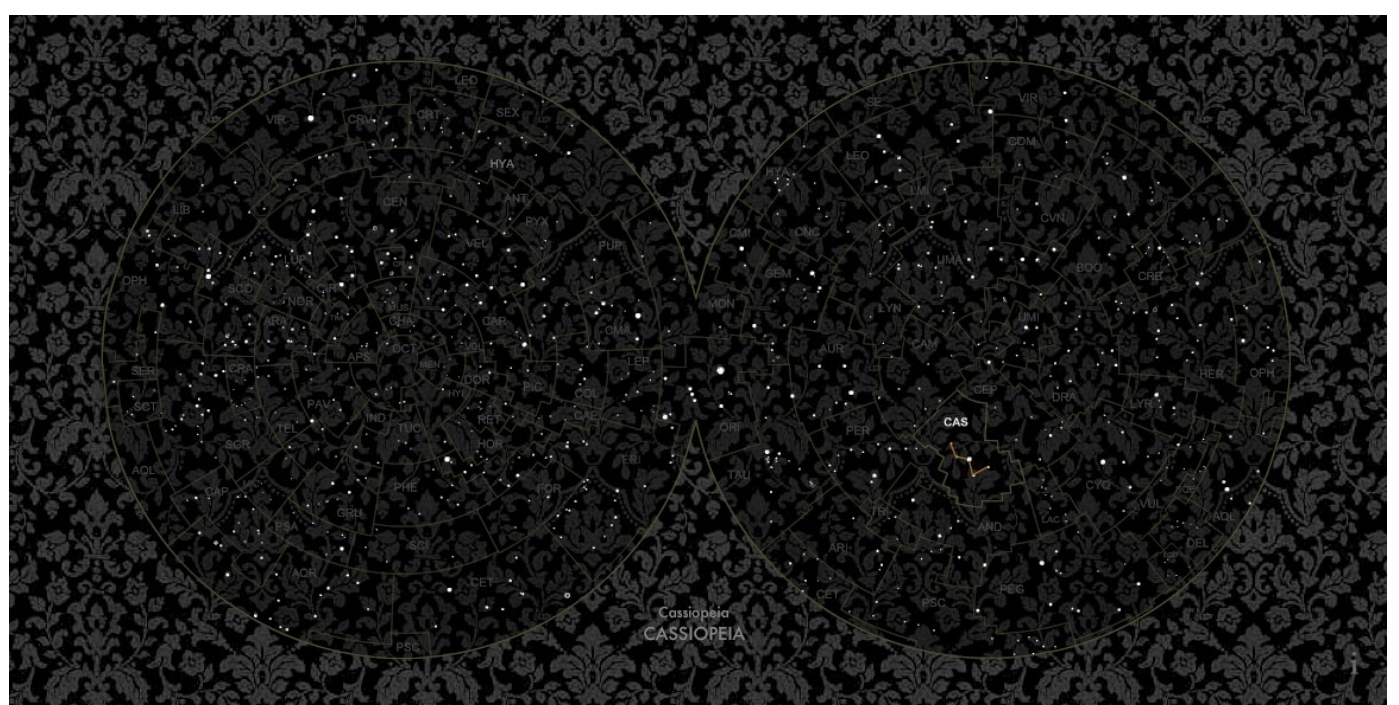

If selected, the constellation contour illuminates in a flashy yellow tone, which indicates its boundaries within the neighboring constellations in the sky. The explorative stars that glow are united in a red-orange light, which shows the "joining dots" of each star within the selected constellation. Meanwhile the sound effect continues on the backstage of the constellation map. Lastly, the name of the constellation appears as a linguistic text at the bottom of the sky map. It is important to mention that the division of both hemispheres is intentionally combined together by constellation 04 Orion that, as aforementioned, is devoted to Ludwig Wittgenstein's biography.

Furthermore, it must be pointed out that there is an icon in the bottom right corner represented by the letter "i" which redirects the reader to specific information regarding the creation and the instructions needed in order to interact with $88 \mathrm{C}$. If the reader is curious and wishes to learn more about the e-lit work, the options: "play intro, instructions, sitemap, credits, close info" appear within the same screen night sky scenario as the constellation map fades away. It is important to indicate that the 
specific instructions regarding the significant use of the "left hand" while reading the e-lit work are given in the above-mentioned instructions' section.

Fig. 4 - Information Contents and Paratextual Instructions, 88 Constellations for Wittgenstein (To Be Played with the Left Hand).

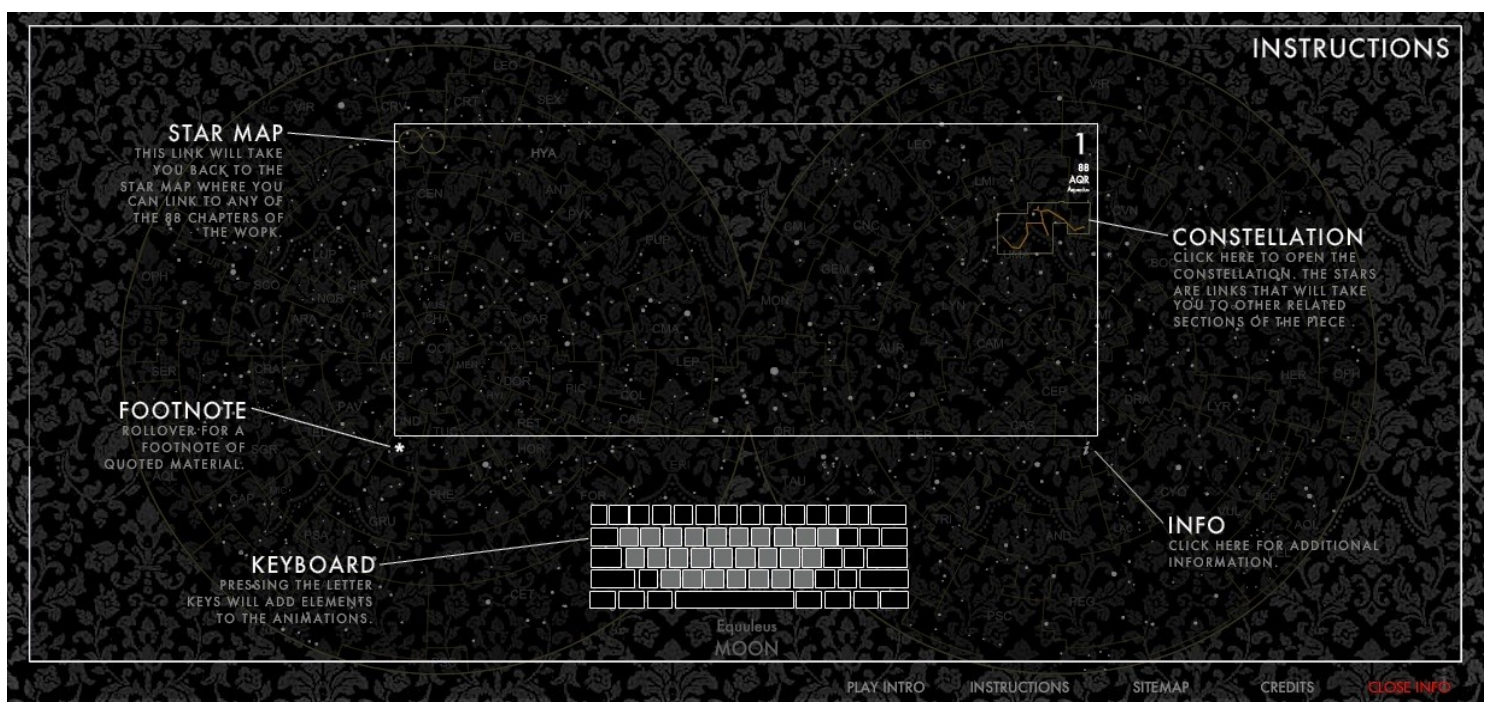

\section{To Be Played with the Left Hand}

The map offers spatial navigation through the interaction of the reader with explorative, interpretative, and configurative links. Explorative because the reader searches in the starry night sky for the constellation she wishes to explore; interpretative because, up to this point, she reflects on the "clicking" pathway she has followed in order to be in that precise time and space; and configurative because she is about to choose her first set of explorative stars so as to construct her way to begin the "story". Apart from that, the reader learns that the story of Ludwig Wittgenstein possesses a multicursal non-linear navigation that allows her to choose among multiple paths from where she can begin.

The reader must not only click on a link but also interpret the denotative name Clark has given to each constellation (e.g. "Cassiopeia (CAS): Cassiopeia"; "Ursa Minor (UMI): Constellations"; "Hydra (HYA): The Limits of Language"; "Orion (ORI): Ludwig Wittgenstein"). Therefore, two things can be pointed out; on the one hand, that manipulation in this part of the navigation relies on the reader's interaction with 
linguistic text, static but degraded images, and a repetitive background sound; and, on the other hand, the fact that the reader's choice of explorative stars is determined by her own encyclopedia; that is, her cultural, political, artistic, philosophical knowledge or, simply, by random curiosity.

\section{Cassiopeia 18 (Cassiopeia): Voices in the Sky}

The multi-voicedness created in $88 \mathrm{C}$ possesses different tinges, times and tunes. In the case of constellation number 18 Cassiopeia (Cassiopeia), these traces go from Greek Mythology to Wittgenstein's diaries written during World War I ${ }^{1}$. Before the text is analyzed, it is important to point out that the reader experiences the story through a spoken narrative; however, as aforementioned, the transcription of the recounted events is provided for a better grasp of the contents. Cassiopeia's story possesses a heterodiegetic omniscient narrator who inserts stories and utterances in the different narrative discourse's levels of the work. As the story flows, these voices gradually unfold, weaving at its pace the narrative's polyphony and intertextuality.

(2) Cassiopeia was a queen who was both beautiful and vain. Her vanity was to cause her great distress. As a punishment, Poseidon put Cassiopeia in the heavens on a chair that revolved around the North Pole so that half the time she was obliged to sit upside down. In his recollections of Wittgenstein, Norman Malcolm notes an uncharacteristically whimsical moment: "Once when we were walking across Jesus Green at night, he pointed at Cassiopeia and said that it was a ' $W$ ' and that it meant Wittgenstein. I said that I thought it was an 'M' written upside down and that it meant Malcolm. He gravely assured me that I was wrong". For the Greeks the W was Cassiopeia's crown as well as a chair. Is it a W or an M? A chair or a crown? A blessing or a curse? It all depends on how you look at it. It depends on your point of view. "The world of a happy man is different from that of the unhappy man", Wittgenstein once said. Wittgenstein struggled with his vanity throughout his life. He was repulsed by his arrogance and yet he aspired to greatness. In a dairy written when Wittgenstein was a soldier in World War I, he wrote: "Oh, how I wish that I could have been something! How I wish that I could have blazed across the sky like a star!" (88C, transcription of Cassiopeia's Constellation)

\footnotetext{
${ }^{1}$ Wittgenstein volunteered for the Austrian army in the First World War and was decorated for his bravery. He sought out particularly dangerous though not suicidal positions, apparently in an effort to test his fearlessness. A death wish and a desire to do his duty to the outmost are also possible motives. He was known by his fellow soldiers for his devotion to Leo Tolstoy's version of the Gospels. Near the end of the war he was captured and worked on the Tractatus Logico-Philosophicus in a prisoner-of-war- camp in Italy. Historical Dictionary of Wittgenstein's Philosophy, p. 199.
}

Texto Digital, Florianópolis, Santa Catarina, Brasil, v. 11, n. 1, p. 287-314, jan./jun. 2015. ISSNe: 1807-9288. 
By means of narrativized speech, the omniscient narrator opens the story by recounting Cassiopeia's myth ${ }^{2}$, which explains the name of the selected constellation, and alludes to the image of the letter "W", evoked by the stars that compose it. The reader finds herself in the extra-diegetic level of the narrative discourse because the first story is being unfolded to her. By these words, the reader learns about Cassiopeia's myth, and therefore the first example of intertextuality by means of a literary reference (Greek Mythology) is announced, "Cassiopeia was a queen who was both beautiful and vain". Moreover, the ideas of circling and rotating are emphasized by the fact that Poseidon punished Cassiopeia for her arrogance by "putting her on a chair that revolved around the North Pole". It is important to underline this fact given that the idea of visualizing something upside down is repeated along the narrative discourse; furthermore, this is fundamental for the construction of the visual puns further presented when experiencing the constellation's semiotic forms, as we shall see below.

The intra-diegetic level of the narrative is introduced when the narrative voice mentions Norman Malcolm's recollections of Wittgenstein ${ }^{3}$; the narrative voice introduces Malcolm and Wittgenstein's figures by presenting a memory that Malcolm shared with Wittgenstein during their Cambridge years. This is presented in the narrative by means of Malcolm's use of reported speech, which is recounted in indirect style, "Once when we were walking across Jesus Green at night, he pointed at Cassiopeia and said that it was a 'W', and that it meant Wittgenstein. I said that I thought it was an 'M' written upside down and that it meant Malcolm. He gravely assured me that I was wrong" (my emphasis). There are two facts that must be underlined; on the one hand, the reader must know that this exact quotation can be

\footnotetext{
${ }^{2}$ Cassiopeia. The mother of Andromeda and so proud of her beauty that she dared to compete with the Nereids or even, according to some writers, with Hera. The goddesses demanded of Poseidon that he should avenge this blow to their self-esteem and he sent a sea monster which laid waste Cassiopeia's land. In order to appease the god's wrath, Andromeda had to be exposed in expiation for the monster to do its worst, but Perseus appeared, freed her and bore her off with him. Cassiopeia was turned into a constellation. The Dictionary of Classical Mythology, p. 91.

${ }^{3}$ Malcolm, Norman Adrian (1911-1990). A was a friend and a student of Wittgenstein who became a well-known philosopher in his own right, working mostly on the philosophy of the mind and epistemology. Malcolm taught for many years at Cornell University and was one of the main routes through which Wittgenstein's ideas entered the United States. His books include Dreaming (1959), Ludwig Wittgenstein, A memoir (1962) and Nothing is Hidden (1986). Historical Dictionary of Wittgenstein's Philosophy, p. 115.
} 
found in Norman Malcolm's Ludwig Wittgenstein, A memoir (1962), which instantly makes it the second example of intertextuality through a literary reference found in Cassiopeia. On the other hand, it is not a coincidence that the key subject of the recounted dialogue is, in fact, the limitlessness of visual representation, and the open stage to different interpretations on a given subject. This is an allusion to Wittgenstein's "Picture Theory" within the Tractatus Logico-Philosophicus (1922) ${ }^{4}$, which states, "Our life has no end in just the way in which our visual field has no limits" (6.4311); "sentences or propositions are pictures of states of affairs in the world" (Historical Dictionary of Wittgenstein's Philosophy, p.145). Therefore, this literary allusion becomes the third example of intertextuality within the narrative discourse.

At this point, the narrative level is meta-diegetic due to the inclusion within the narrative discourse of the recounted dialogue between Malcolm and Wittgenstein. The voice of Wittgenstein referred to by Malcolm's indirect style is heard for the first time. The fact of recounting a conversation to learn about the character's remarks adds not only an additional philosophical moment to the story, but also dynamism to its parallel visualization. In the frame of Cassiopeia's Myth within the recounted dialogue, the omniscient narrator inserts Malcolm and Wittgenstein discussion - parallel to the narrator and the narratee's evoked one - regarding the endless problems of representation while looking at Cassiopeia's visualization in the sky. As the story goes back to the intra-diegetic level of the narrative, the referred conversation opens the space for the upcoming questioning that the narrative voice is about to address to the reader, "Is it a $\mathbf{W}$ or an $\mathbf{M}$ ? A chair or a crown? A blessing or a curse?" (my emphasis). It must be brought to the reader's attention that these questions are strictly related to the visual and mental puns that through diverse voices the narrative discourse evokes; what is more, it can even be suggested that the narrative voice condenses in the following words what it seems to be the leitmotiv

\footnotetext{
${ }^{4}$ The Tractatus Logico-Philosophicus (1922). Originally called Logisch-Philosophische Abhandlung ("Logico-Philosophical Treatise") was the only book published under Wittgenstein's name in his lifetime. In the preface to the book he says that its value consists in two things: "that thoughts are expressed in it" and "that it shows how little is achieved when these problems are solved." The book consists of numbered propositions in seven sets. At the end of the book (proposition 6.54) Wittgenstein says: "My propositions serve as elucidations in the following way: anyone who understands me eventually recognizes them as nonsensical." Op.cit. p. 185.
}

Texto Digital, Florianópolis, Santa Catarina, Brasil, v. 11, n. 1, p. 287-314, jan./jun. 2015. ISSNe: 1807-9288. 
of the story, "It all depends on how you look at it. It depends on your point of view" (my emphasis).

As the story continues, the narrative voice integrates once again Wittgenstein's discourse; however, this time it is done by means of reported speech. "The world of a happy man is different from that of the unhappy man', Wittgenstein once said". This quotation stands as the fourth example of intertextuality via a literary reference, given that this philosophical phrase belongs to a larger text found in the Tractatus LogicoPhilosophicus (1922).

If the good or bad exercise of the will does alter the world, it can alter only the limits of the world, not the facts-not what can be expressed by means of language. In short the effect must be that it becomes an altogether different world. It must, so to speak, wax and wane as a whole. The world of the happy man is a different one from that of the unhappy man. (6.43) (my emphasis).

Furthermore, towards the end of the story, the narrative voice goes back to narrativized speech to point out a few facts regarding Wittgenstein's personality and life, the purpose of such, being the inclusion of the last example of intertextuality via a literary reference, which refers to a precise phrase in Wittgenstein's diaries written during World War I. It is important to bring to the reader's attention that these diaries, known as Notebooks 1914-1916 ${ }^{5}$, were later published. By quoting, "Oh, how I wish that I could have been something! How I wish that I could have blazed across the sky like a star!"; the narrative voice underlines several meanings and associations worth mentioning.

Firstly, the fact that Wittgenstein is longing for significance (echoes of questions of existentialism and metaphysics in the Tractatus Logico-Philosophicus); therefore, he

\footnotetext{
${ }^{5}$ These notebooks of Wittgenstein's were edited by G.H. von Wright and G.E.M. Anscombe. They show Wittgenstein working through the ideas that resulted in his Tractatus Logico-Philosophicus. He also sets out quite clearly here some of his ideas about ethics, including thoughts on God, the meaning of life, and suicide. The Notebooks is thus an interesting and instructive book, but of course must be used with care for interpreting the Tractatus, since any remarks found only in the Notebooks might well have been left out because Wittgenstein changed his mind about them, as he appears to do a number of times within the Notebooks itself. Historical Dictionary of Wittgenstein's Philosophy. pp. $131-132$.
}

Texto Digital, Florianópolis, Santa Catarina, Brasil, v. 11, n. 1, p. 287-314, jan./jun. 2015. ISSNe: 1807-9288. 
compares himself to a blazing star. Secondly, the fact that a star shines, brightens, and in a way possesses its own fire (light); by this, the narrative voice brings together the following events, the myth of Cassiopeia, the starry night under which Malcolm and Wittgenstein were walking in Cambridge, the discussion they held about the representation of the Cassiopeia's constellation in the sky, Wittgenstein's recollections of the war scenario he lived during World War I, and lastly, the ephemerality of a star blazing across the sky as if it all were a sudden outburst: an emotion.

Even though, this is not a precise example of "aesthetics of the ephemeral", which, as defined by Alexandra Saemmer, consists of "letting the work slowly decompose, accepting that, through its changing forms and updates, unexpected mutations may even, sooner or later, lead to the obsolescence of the artistic project" (2009, part 1). In my view, the blazing star evokes the ephemeral in a different way; that is to say, the ephemeral is represented by the aesthetics of brevity, and motion within the shooting star, which parallels to the representation of the moving text that describes the same action. This fact clearly stands as an example of the figure of animation ciné-gramme (SAEMMER, 2013, part 4) because the text says precisely what the motion represents. "Oh, how I wish that I could have been something! How I wish that I could have blazed across the sky like a star!" (Cf. Fig. 5)

As it has been shown, active intertextuality and multiple voices live in Cassiopeia's spoken narrative. Although, as it will be explained later, physical interactivity (gestural manipulation) is not mainly present, the interactivity within the reader's mind in terms of literary associations is high; thus, in my view, literary communication-association is highly underlined in the reader's mind. Likewise, in the previous examples, it must be noted that polyphony and intertextuality are connected to the act of memory; to put it in other words, each voice represents a world: Cassiopeia and Poseidon represent the echoes of Greek Mythology; the voice of Norman Malcolm represents two things, the Cambridge period in Wittgenstein's life, as well as, the gatherer of recollections that later became a memoir; the voice of the Austrian philosopher represents his writings, philosophy, wishes, ambitions, and fears; all of which are expressed within different settings and different time frames, e.g. Cambridge, World War I, Notebooks 
1914-1916, Tractatus Logico-Philosophicus (1922), the starry night of the conversation. In other words, by mentioning the act of memory, I do not only refer to the mind's capacity of making associations by means of literary threads (and now by means of plurisemiotic threads), but also to the challenge of weaving stories and being able to aesthetically weave all the information that these voices swiftly offered to us. These voices bring along their own historical, philosophical and aesthetical contexts, which without doubt add new literary tinges to the e-lit work's new context within the electronic medium that - by experiencing the oeuvre-, the reader creates.

\section{Grasping Time}

One of these new tinges is temporality. In order to develop this section of the analysis, I will follow Raine Koskimaa's classification of "temporal possibilities in programmed texts" (limiting reading time, delaying reading time, limiting the reading possibilities, temporally evolving texts); as well as, his classification of "temporal levels for cybertexts with narrative content" (user time, discourse time -pseudo time and true time-, story time, system time) (KOSKIMAA, 2010, p. 134-137). First and foremost, it must be pointed out that constellation number 18 Cassiopeia is presented by means of a Flash vignette, which suggests from the start that time is controlled by the system (transient texts). However, although Cassiopeia's spoken narrative time within the Flash video has an estimated duration of one minute thirtysix seconds (1'36") — this being the time measured until the narrative voice ceases to speak - the Flash video continues (non-stoppable) voiceless, soundless but not motionless, until the reader decides to explore a new star.

\section{Mind the Gap}

Taking this into account, I consider that in terms of limiting reading time there might be no difficulties when reading the linguistic texts that appear in the Flash video - a) Cassiopeia; b) Wittgenstein; c) Malcolm; d) Wittgenstein' (the linguistic text is displayed differently); e) M and $\mathrm{W}$ (visual puns showing the letter upside down)-; 
however, there might be difficulties when reading and listening simultaneously to the last and only quotation that appears as moving linguistic text at the bottom of the screen, "Oh, how I wish that I could have been something! How I wish that I could have blazed across the sky like a star". Therefore, if the period is not long enough, the reader might be forced "to read on the edges of apprehension" (KOSKIMAA, 2010, p.135). Hence, the "blazing" linguistic text represented by Wittgenstein's quotation can either be fully appreciated or only partially, as the reader experiences the e-lit work; which, as pointed out by Eskelinen, in terms of presentation speed, perception, and cognition, "This kind of arrangement may, of course, serve as a wide variety of aesthetic purposes" (2012, p.152) (my emphasis), as we shall see later (e.g. catachretic animation effect).

In terms of delaying reading time, if, as suggested, time is considered to be controlled by the system, therefore the reader cannot rewind or forward the Flash video - as she would freely move through the pages of a book. Firstly, she ought to wait for the video to start (delaying reading time) -occasionally the reader is accompanied by a quotation from the Tractatus while the e-lit work uploads, which inserts a second reading time -meta reading time- by making the reader "read" while waiting to "read"-; and, secondly, she ought to wait for the video to finalize in order to be able to play it again. However, it is possible for the reader to pause or stop the Flash video by clicking either on the icon of the constellation map (upper left corner) or on the icon of Cassiopeia's constellation (bottom right corner) — similar to making a pause while reading a book. Nevertheless, in both cases the pause cannot be timemeasured; and, more importantly, even if the reader stops she cannot rewind the video to re-read (re-view) a specific scene. In order to continue her reading she needs to click back on the main frame of the video presentation so that the narrative will continue its pace until, as previously mentioned, the narrative voice ceases to speak.

Moreover, when speaking of limiting the reading opportunities of a programmed text, it can be pointed out that Cassiopeia can be experienced as many times as the reader wishes (unlimited, non-measurable). Cassiopeia can freely be accessed 
online within the frame of $88 \mathrm{C}$ via the ELC2; therefore, it is not an e-lit work that has a limited access time nor an e-lit work that can be read only once - as it is the case of other e-lit works. Cassiopeia (88C) has been archived and preserved within the ELC2 to be accessed freely by general public without expiration time frames. In other words, it is not likely to disappear or become inaccessible for the reader, as it occasionally happens with some electronic texts.

Cassiopeia cannot be classified within temporally evolving texts, given that to fulfill this category it is needed to add something by the author or by the reader, or both (KOSKIMAA, 2010, p. 135). In Cassiopeia's electronic pattern within 88C even if something can be altered or added in terms of text, image or sound, it cannot be permanent (the system does not save the changes); therefore, there is not authorial intrusion whatsoever like in other e-lit works (e.g. Poesía asistida por computadora by Eugenio Tisselli, 2006; RepeatAfterMe, 2012 by Jörg Piringer). It is important to mention that though Cassiopeia might experience a quick change (additional music, sound, image, text) by means of the secret of the left hand, when the reader switches to another constellation, these changes are lost and the text goes back to its organic electronic state. This is an example of "aesthetics of the ephemeral", (SAEMMER, 2009, part 1) because even though the work allows the reader to make changes, and additions on it, as pointed out by Saemmer, "the reader is integrated into the observed system, but the traces he leaves on a poetic work are governed by the same principle of obsolescence as every surface event" (Idem) (my emphasis); however, as mentioned above, if we consider that the system does not save these changes, then the verbal, visual, and aural media additions become simply ephemeral.

\section{Time Condensed in Quotations}

When speaking of temporal levels for cybertexts with narrative content (KOSKIMAA, 2010, p. 136), the user time in Cassiopeia is understood as the time the reader spends reading (experiencing the text); in other words, the number of times the reader can access the text and re-read it; and, therefore the sum-up in hours, 
minutes or seconds of these reading times (unlimited; non-measurable). When reflecting upon this concept, it is important to bear in mind that Cassiopeia is just one of the 88 constellations of what the narrative voice considers the whole story, "this story is about a man named Wittgenstein...he was a philosopher...his life was a series of moments and our story is a series of constellations" (88C, transcription 1) (my emphasis). This means that I am only considering the user time of one single explorative star. However, if the reader is to follow a certain path, as I have: 18 Cassiopeia (Cassiopeia), 12 Ursa Minor (Constellations), 59 Hydra (Limits of Language), 04 Orion (Ludwig Wittgenstein), then the approximate user time will be expanded but still it is unlimited and non-measurable; in a way, resembling the universe.

Thus, bearing in mind that the reading time definitely depends on the system time, and that the system time refers to the running time it has been given to Cassiopeia within $88 \mathrm{C}$; one might think that the reading time can be measured from the moment the reader clicks on Cassiopeia in the main constellation map until the Flash video is over; however, this is not true. In Cassiopeia, the Flash video if not manipulated by the reader, never stops. It is the reader who triggers the change (ergodic time); and either expands or shortens her own reading time. It is important to mention at this point that when the reading time gets expanded at the end of the spoken narrative, this is due to the additional semiotic units that the reader can add by means of the secret of the left hand (e.g. sounds, moving images, moving text).

Since, to my view, each explorative star has its own system time; it must be brought to the reader's attention that even though in some cases the spoken narrative stops, and the Flash video does not; there are some other occasions in which the spoken narrative and the Flash video stop at the same time, as it shall be shown when analyzing other explorative stars (e.g. Hydra (HYA) The Limits of Language). Lastly, if the reader wishes to know the total system time of $88 \mathrm{C}$, this would be the sum-up time of each of the Flash vignettes that compose the e-lit work, but as suggested, this is simply non-measurable and unlimited. Different would be so, if $88 \mathrm{C}$ were a film about Wittgenstein's life; for instance, one single Flash video with duration (screen 
time) of one hour twenty-four minutes, which might be considered as the total true time and system time.

In terms of discourse time, there are two ways to explore this temporal level. The first one is to consider that discourse time is linked to the system time, given that in the case of text-controlled time e-lit works, both times are connected (e.g. Hydra (HYA): The Limits of Language). However, in Cassiopeia the spoken narrative discourse lasts approximately 1'36" within a system time that cannot be measured because it does not stop by itself. Hence, the discourse time of the story is equivalent to the time the reader listens to the narrative voice (1'36"), that is the true time (screen time). If we consider Cassiopeia to be an oral narrative, then there is no pseudo time at all; and it could be suggested that the true time is equivalent to the time of the narrative discourse (1'36"). However, if the discourse time is analyzed from the transcription of the spoken narrative that was used to explore polyphony and intertextuality in Cassiopeia; then the discourse time (the time of the narrative discourse) does posses a pseudo time and certainly a true time. In this case, the length of the transcription in the format of the present article is twenty lines (pseudo time: spatial measure); and the duration of the true time is equivalent to the duration of the discourse time (1'36"), but not to the duration of the system time, which as previously said it is non-measurable and open to manipulation by the reader (dynamic time).

When exploring story time there are certain temporal points of reference that help the reader to situate the events that are being narrated in historical time. Even though the events are narrated in different order within the story; it can be suggested that they have a chronological order outside of it. First and foremost, the reader must bear in mind that the story $(88 \mathrm{C})$ is based on the events that happened during Wittgenstein's life (1889-1951), as well as, in the different locations these events took place (Vienna, Berlin, Manchester, Jena, Cambridge, Norway, Krakow, Russia, Dublin, etc.) -all of which, can be historically verified. Furthermore, the voices of polyphony that revolve within each explorative star, allow the reader to listen to specific time echoes arranged in a completely different order. In Cassiopeia, for 
example, these echoes date from Ancient Greece (8th to 6th centuries BC to the end of antiquity $600 \mathrm{AD}$ ) to the $20^{\text {th }}$ Century. The way to present the duration of these events is quite interesting, for it seems as if time were intentionally condensed in quotations (spoken, written or both), underling by its pace, the high traces of intertextuality found in the narrative discourse.

Each one of these events has its own true time within the discourse time of one minute and thirty-six seconds (1'36"). However, they did not all happen at the same time (historical time). For example, when the narrative voice summarizes Cassiopeia's myth, the reader immediately situates herself in Ancient Greece; but seconds later, by means of a (spoken) quotation inserted as a recollection, the reader is brought to the $20^{\text {th }}$ Century, specifically to the period Malcolm and Wittgenstein spent together in Cambridge (1938-1951); then again the narrative goes back in historical time by the inclusion of the next (spoken) quotation "The world of a happy man is different from that of the unhappy man" (Tractatus LogicoPhilosophicus, 1922); and finally to close up the narrative discourse the only (written and spoken) quotation that goes back in historical time referring to Wittgenstein's diaries during the years of WWI (1914-1918), is announced: "Oh, how I wish that I could have been something! How I wish that I could have blazed across the sky like a star" (Notes 1914-1916).

In this last example, it can be argued that if "the duration of presentation usually equals the time of perception (hearing or viewing)" (system time); therefore, "as the text is transient and has verifiable duration, the reader must adjust his reading speed to the speed and duration of presentation and can no longer take all the time he may need to read the text" (ESKELINEN, 2012, p. 135) (Cf. limiting reading time). Hence, the challenge when reading Cassiopeia (88C) relies not only on merging all temporal levels together, but also on making associations among them in order to construct or deconstruct their meaning. The reader must realize that layering time through dynamics in electronic literature creates unlimited possibilities for controlling, embroidering, and adding complexity to hypermedia narrative discourse (discourse time); given that the classical narrative categories of time (order, duration, and 
frequency) can be interestingly manipulated via system time and reading time, as it shall be studied in further analyses.

\section{Is it a W or an $M$ ?}

Fig. 5 - Screen shots from 18 Cassiopeia (CAS) shown in order of appearance (upper left, upper right, bottom left, bottom right), 88 Constellations for Wittgenstein (To Be Played with the Left Hand).

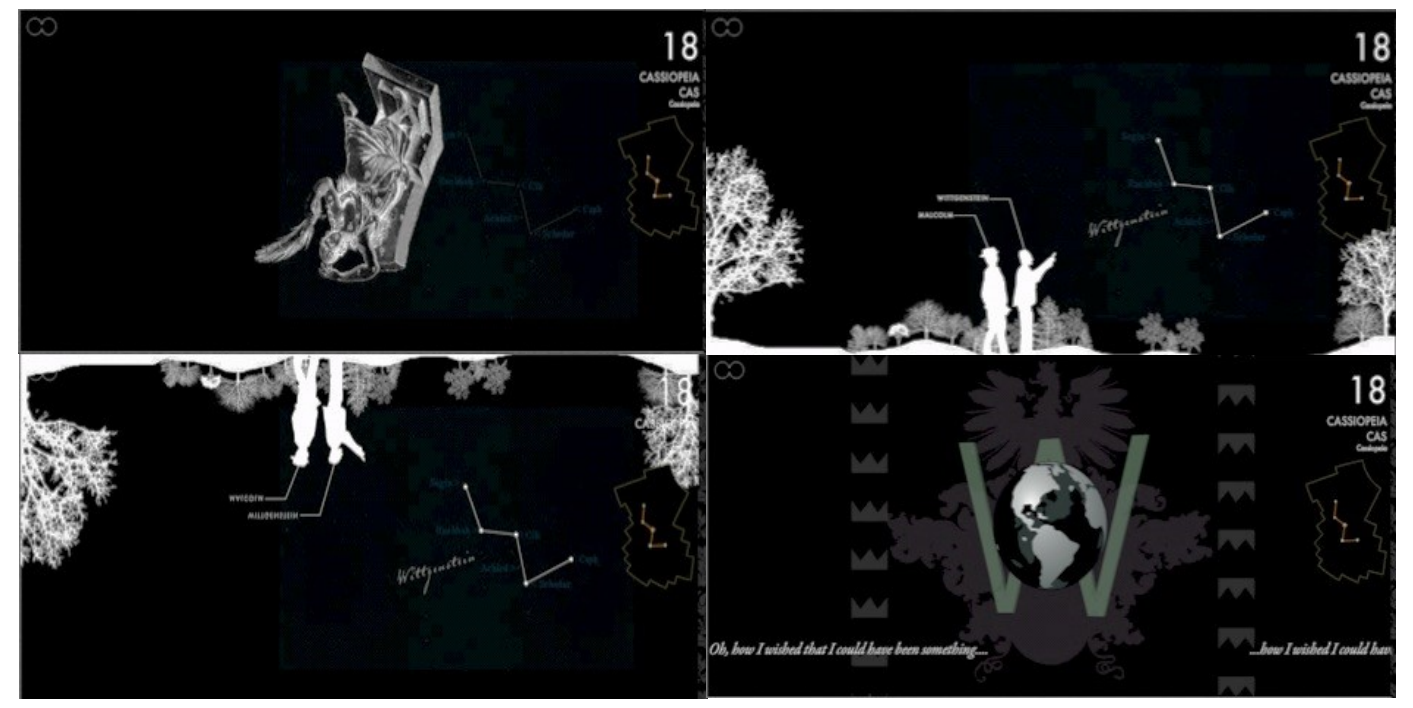

Each individual constellation in Clark's e-lit work is arranged the same way in terms of paratexts. The Flash Video is framed in a rectangle with a white delineation that serves as a screen for the presentation. Within the rectangle, on the right upper corner the number and the name of the chosen constellation are shown; below this information the icon of the constellation — resembling its visual appearance in the sky hemispheres - is displayed. The reader learns that each explorative star connects her to other stories, which emphasizes the idea of interactive "tour de force" and "non-linearity" within the main story mentioned in the ELC2 presentation of 88C. As aforementioned, in Cassiopeia, these interconnected stars are: Ludwig Wittgenstein (04) (Epsilon Cassiopeiae), Coded Remarks (19) (Delta Cassiopeiae), LOL (86) (Gamma Cassiopeiae), Cambridge (21) (Beta Cassiopeiae), and Constellations (12) (Alpha Cassiopeiae). The option of returning to the constellation map is available by clicking on an icon that resembles a small constellation map (upper left corner). Additionally, there is the information icon that appears at the bottom right corner of 
the screen, which redirects the reader to the following options, "play intro, instructions, sitemap, credits, close info".

As the spoken narrative begins, the mélange of semiotic systems unfolds to the reader. As explained in the section of intertextuality and polyphony in Cassiopeia, the narrative voice is composed of multiple stories that possess different time periods. The meaning of these stories is created through the interplay of text, image, sound and motion; but the challenge of creation relies precisely on associating and analyzing the coherence of these individual meanings (joining modes through media) in order to visualize and comprehend the meaning of the whole message (pluricode couplings, coherent couplings, de-coherent couplings) (SAEMMER, 2012, p. 321330).

In Cassiopeia, the image of a crown appears at the same time as the linguistic text, "Cassiopeia", creating fantastic associations, visual puns, and modifying meanings among crown, queen, and Cassiopeia. The image of Cassiopeia as a queen (goddess in the chair) is also displayed. In order to express the limits of representation in allusion to Wittgenstein's philosophy — "Our life has no end in just the way in which our visual field has no limits" (Tractatus Logico-Philosophicus, 6.4311), Clark makes the verbs of the oral narrative the performers of the screen motion. In other words, by enunciating, "revolved" the image of Cassiopeia rotates. Therefore, the narrative voice and the rotating image underline the idea of upside down by creating coherent couplings among image, audio and motion. This is an example of the above-mentioned figure of animation ciné-gramme, because once again the motion represents what the oral text is saying (SAEMMER, 2013, part 4).

The following example is "walking", when the narrative voice pronounces, "walking", the figures of Malcolm and Wittgenstein appear walking on the screen; along with a linguistic text indicating the name of each character (new visual semiotic system). Likewise, this is an example of coherent coupling among image, audio and motion; and it can also be read as a representation of memory by means of a black and white recollection, and a sudden change in sound, which parallels not only with the "whimsical moment" of the conversation, but also with the "whimsical features" of the 
constellation's mise en scène. A similar pattern happens with "pointed", as the word is pronounced by the narrative voice, Wittgenstein's figure points at Cassiopeia's constellation. The constellation illuminates in the night sky suggesting the image of the letter "W" which stands as an example of creation of visual vocabulary. This correspondence is followed by the appearance of the second linguistic text representing "Wittgenstein" in the sky, which is an example of addition of visual vocabulary by means of a new visual semiotic system.

The following example of coherent coupling (image is coupled with movement) is represented when the whole screen turns upside down to emphasize the double perception of the constellation's shape; "I said that I thought it was an 'M' written upside down and that it meant Malcolm" (my emphasis). This specific moment can be an example of motion represented as an iconic sign, which suggests that the correspondence between audio and visual movement might have an extended reading. That is to say, the movement effect-association can be read as a visual exaggeration, and therefore, produce in the reader the effect of the rhetorical figure of hyperbole (SAEMMER, 2013, p. 4). To emphasize this effect, the rotating letters W and $M$, and the images of a chair and a crown appear on the screen coupled with the audio, "Is it a $\mathbf{W}$ or is it an $\mathbf{M}$ ? A chair or a crown?" (my emphasis); the mingling of modes evoking the rotating images of $\mathrm{M}, \mathrm{W}$, chair and crown create an intertextuality of images (fantastic associations and allusions) as the narrative voice emphasizes "it all depends on how you look at it, it all depends on your point of view".

Lastly, by introducing the quotation, "The world of a happy man is different from that of the unhappy man" (Tractatus Logico-Philosophicus, 6.43) different associations are made. In the first place, a globe rotating is shown as well as the rotating letter "W" in the background. It is interesting to see that the letter "W" and the gyratory image of the world couple with the narrative voice as it pronounces World War I (my emphasis). This is an example of visual puns emerging from visual vocabulary where the association between audio, motion, image, and linguistic text is fundamental. Secondly, the quotation, "Oh, how I wish that I could have been something! How I wish that I could have blazed across the sky like a star!", creates a combination of action, language and expression; such integration is needed in order to construct the 
effect of ephemerality. Therefore, two aspects must be underlined; in the first place, as we have seen, the reading time is not enough to grasp the meaning of what is written and moving, which might produce a catachretic animation effect (SAEMMER, 2010, p. $174-175)^{6}$. In the second place, the fact that the text appears and disappears forces the reader to question its true meaning and consequently to create a metaphoric effect of dead, life, and memory through vanishing visual semiotics, "Our life has no end in just the way in which our visual field has no limits" (Tractatus Logico-Philosophicus, 6.4311).

\section{The Secret of the Left Hand}

Interaction in Cassiopeia is linked to adding. As explained before, the fact that Cassiopeia is experienced through Flash video, forces the reader to view more than to interact with the e-lit work. However, as pointed out in the paratextual information of $88 \mathrm{C}$, Clark suggests that the reader uses the left hand in order to activate and therefore interact with the hidden features of the electronic oeuvre. In Cassiopeia, the secret of the left hand, allows the reader to add the image of a crown - formed with the white silhouette of the letter "W", whenever she wishes throughout the hypermedia narrative discourse. The image of the crown appears repeatedly in one vertical line on the left side of the screen. Pressing the keys "W" and "M" activates this function; the reader can deactivate it (the image gradually vanishes); by pressing any key from "A to $Z$ ". By adding images, the reader discovers new text and modifies the existing one. Therefore, on the one hand, she adds new meaning to the hypermedia narrative discourse, and, on the other hand, she also adds feeling to her reading experience, "And here is yet another dimension that needs to be added to make discourse and multimedia analysis faithful to the world of meaning: seeing that there is no meaning without feeling" (LEMKE, 2013, p. 85) (my emphasis). This means that among all these associations the reader might also experience the

\footnotetext{
${ }^{6}$ In her essay, "Digital Literature -A Question of Style", Alexandra Saemmer states that other examples of catachretic effects can be "the emergence and the eclipse" of the words when they point out the title of a poem; or "the transpositions" of scrolling names at the end of films (2010, pp. 174175).
} 
"aesthetics of re-enchantment", the fourth approach on the lability of the electronic device (SAEMMER, 2009, part 1), which, "mystifies the relationships between the animated words and images, between the sounds and gestures of manipulation in a digital artwork, in order to advocate an "unrepresentable", something that words can not describe and yet, that one can "feel" by experiencing the work" (Idem) (my emphasis).

Finally, in terms of manipulation through interaction, it should be noted that these images could be added either throughout the presentation of the Flash video or at the end. However, if activated at the end, by adding images ("semiotic units of manipulation") (SAEMMER, 2013, p. 4) the reader adds time, and therefore expands reading time, manipulates discourse time, and metaphorically operates system time. Likewise, by clicking to pause, exit or replay during the video presentation, the reader manipulates reading time and discourse time. Lastly, in Cassiopeia, these "semiotic units of manipulation" are only represented by the repeatedly image of the crown. However, when analyzing other explorative stars (Cf. 12 Ursa Minor, Constellations; 04 Orion, Ludwig Wittgenstein); the secret of the left hand will reveal to the reader not only images but also new verbal and aural semiotic systems (text and audio), which needless to say, will modify meaning, "feeling", and time in the hypermedia narrative discourse.

\section{Conclusion}

Throughout the analysis of hypermedia discourse elements in Cassiopeia, high traces of literary works that inhabit and interlace not only within Cassiopeia but also within the universe of $88 \mathrm{C}$ were found. By means of "pluricode couplings" specific examples of intertextuality and polyphony skillfully underline the importance of Wittgenstein's philosophy, Greek Mythology, and other literary works related to Wittgenstein's life and works. After putting to practice the selected new media literary theories (temporal possibilities in programmed texts; temporal levels for cybertexts with narrative content; pluricode couplings, lability of digital works) to Cassiopeia's constellation within Clark's e-lit work; the analysis shows that some of the propositions within the theories can indeed be found in Cassiopeia's hypermedia 
narrative discourse; and more importantly, that some of them even connect to each other or affect the other (e.g. polyphonic pluricode couplings create digital rhetoric effects within the framework of the lability of the electronic device, i.e. ciné-grammes, hyperboles; the approach "aesthetics of the ephemeral" alters reading time and discourse time; "semiotic units of manipulation" allow the reader to expand reading time, as well as manipulate discourse time and trigger ergodic time; and finally, the appearance of catachretic effects may be caused by reading on the edges of apprehension, limiting reading time). The aesthetic experience of critically reading Cassiopeia through the lens of new media literary theory made me rethink about the propensity to explore e-lit works only on the surface, leaving aside that it is precisely on this mutable and complex à-voir surface where the unexplored literary terrain awaits.

\section{LENDO ESTRELAS DA NARRATIVA HIPERMÍDIA: 88 CONSTELATIONS FOR WITTGENSTEIN DE DAVID CLARK. ABORDAGEM ANALÍTICA DE CONSTELLATION 88 CASSIOPEIA}

RESUMO: Este artigo apresenta uma abordagem para analisar elementos de hipermídia encontrados no discurso de "Cassiopeia", uma das constelações que compõem 88 Constellations for Wittgenstein (To Be Played with the Left Hand) (2011), pelo artista [ ] David Clark. Embora existam muitas abordagens para o tema da literatura eletrônica, ainda há muitas obras inexploradas esperando para serem estudadas, o que, indubitavelmente, levantará questões sobre a literalidade da literatura eletrônica. Este artigo descreve brevemente as questões de representação, temporalidade, semióticas, interação e manipulação nesta constelação específica do trabalho acima mencionado. $O$ artigo utiliza teorias literárias específicas do meio digital (possibilidades temporais em textos programados, níveis temporais para cibertextos com conteúdo narrativo, acoplamento pluricode, instabilidade de obras digitais) a fim de examinar as nuances e gradações da textualidade eletrônica e da recepção literária. A análise mostra que a manipulação e a interação do usuário com a obra afetam certos elementos do discurso narrativo hipermídial e sugere novas possibilidades de interpretação temporal e semiótica.

PALAVRAS-CHAVE: Análise do Discurso. Literatura Eletrônica. Narratividade. Semiótica. Temporalidade.

\section{References}

BOUCHARDON, Serge; HECKMAN, Davin. 2012. "Digital Manipulability and Digital Literature". Electronic Book Review. Last access November 15, 2014. URL: <http://www.electronicbookreview.com/thread/electropoetics/heuristic>. 
CLARK, David. 88 Constellations for Wittgenstein (To be Played with the Left Hand). Electronic Literature Collection Volume 2, 2011. Last access November 4, 2014, URL: <http://www.88constellations.net/>.

- "Author Description of 88 Constellations for Wittgenstein (To be Played with the Left Hand)". Electronic Literature Collection Volume 2, 2011. Last access November 4, 2014, URL: <http://collection.eliterature.org/2/works/clark_wittgenstein.html>.

ENSSILIN, Astrid. "Hypertextuality”. In RYAN, M. L.; EMERSON, L.; ROBERTSON, B. J., The Johns Hopkins Guide To Digital Media. Baltimore: Johns Hopkins University Press, p. 258-265, 2014.

Electronic Literature Collection Volume 2, 2011. Last access November 4, 2014, URL: <http://collection.eliterature.org/2/>.

ESKELINEN, Markku. Cybertext Poetics: The Critical Landscape of New Media Literary Theory. USA: Continuum, 2012.

GENETTE, Gérard. Paratexts: Thresholds of Interpretation. Cambridge: Cambridge University Press, 1997 [1987].

- Narrative Discourse. An Essay in Method. New York: Cornell University Press, 1980 [1972].

GRIMAL, Pierre. (Ed.) The Dictionary of Classical Mythology. Translated by A. R. Maxwell-Hyslop. First published in French as Dictionnaire de la Mythologie Greque et Romaine [1951]. Great Britain: Blackwell Reference, 1985.

KOSKIMAA, Raine. "Approaches to Digital Literature: Temporal Dynamics and Cyborg Authors". In SCHÄFER, J.; SIMANOWSKI, R.; GENDOLLA, P. (Eds.), Reading Moving Letters: Digital Literature in Research and Teaching. Bielefeld: Transcript, p. 129-143, 2010.

LEMKE, Jay. "Multimedia and Discourse Analysis". In GEE, J. P.; HANDFORD, M. (Eds.), Routledge Handbook of Discourse Analysis. USA-Canada: Routledge, p. 7989, 2013.

PIRINGER, Jörg. RepeatAfterMe. Anthology of European Electronic Literature. 2012. Last access November 18, 2014. URL:

<http://anthology.elmcip.net/works/repeatafterme.html>.

RICHTER, Duncan (Ed.) Historical Dictionary of Wittgenstein's Philosophy. Historical Dictionaries of Religions, Philosophies, and Movements, No. 54. USA: Scarecrow Press, INC, 2004.

SAEMMER, Alexandra. "Some reflections on the iconicity of digital texts". Language \& Communication, v. 33, n.1, p. 1-7, 2013. 
"Animation and manipulation figures in digital literature and the poetics of (de-) coherence". Literary and Linguistic Computing, v. 27, n. 3, p. 321-330, 2012.

— "Digital Literature-A question of Style". In SCHÄFER, J.; SIMANOWSKI, R.; GENDOLLA, P. (Eds.), Reading Moving Letters: Digital Literature in Research and Teaching. Bielefeld: Transcript. p. 163-182, 2010.

— 2009. "Ephemeral passages_La Série des U and Passage by Philippe Bootz. A close reading". Dichtung-Digital. Last access November 15, 2014. URL:

<http://www.dichtung-digital.org/2009/Saemmer/index.htm>.

TISSELLI, Eugenio. Poesía asistida por computadora. 2006. Last access November 18, 2014. URL: <http://www.motorhueso.net/pac/>.

WITTGENSTEIN, Ludwig. Tractatus Logico-Philosophicus. Translated by D. F. Pears and B. F. McGuinness. London: Routledge \& Kegan Paul. (1961) [1922].

Texto recebido em: 10/07/2015.

Texto aceito em: 28/07/2015. 